\title{
Histological evaluation of bone repair using $\beta$-tricalcium phosphate
}

\author{
Riedel Frota ${ }^{1}$, Valdemiro-Amaro Da Silva-Júnior ${ }^{2}$, Marcelo Teixeira ${ }^{3}$, Ana-Paula-Veras Sobral ${ }^{4}$, Emanuel- \\ Dias-de Oliveira e Silva ${ }^{5}$, Márcia-María-Fonseca Da Silveira ${ }^{6}$, Adelmo-Cavalcanti Aragão-Neto ${ }^{7}$
}

\author{
${ }^{1}$ Student, PhD Program in Oral and Maxillofacial Surgery, FOP/UPE \\ ${ }^{2} \mathrm{PhD}$ of Histology and Assistant Professor of Veterinary Histology, UFRPE \\ ${ }^{3}$ Student, PhD Program in Veterinary Surgery and Assistant Professor of Veterinary Physiology, UFRPE \\ ${ }^{4} \mathrm{PhD}$ in Oral Pathology and Assistant Professor of Oral Pathology, FOP/UPE \\ ${ }^{5}$ Chairman of Oral and Maxillofacial Surgery Residence, FOP/UPE \\ ${ }^{6} \mathrm{PhD}$ of Stomatology and Assistant Professor of Stomatology, FOP/UPE \\ ${ }^{7}$ Student, Graduation program in Odontology, UFPE
}

Correspondence:

Oral and Maxillofacial Surgery, FOP/UPE

Brazil

riedelfrota@uol.com.br

Received: 25/02/2010

Accepted: $31 / 05 / 2010$
Frota R, Silva-Júnior VA, Teixeira M, Sobral APV, Silva EDO, Da Silveira MM, Aragão-Neto AC. Histological evaluation of bone repair using $\beta$-tricalcium phosphate. Med Oral Patol Oral Cir Bucal. 2011 Mar 1;16 (2):e190-4.

http://www.medicinaoral.com/medoralfree01/v16i2/medoralv16i2p190.pdf

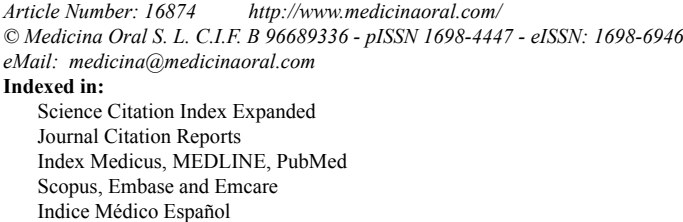

\begin{abstract}
Objectives: The aim of the present study was to evaluate bone repair in defects induced in the cranium of Wistar rats using $\beta$-tricalcium phosphate. Study Design: In this research, we used 30 rats, randomly distributed in three groups of 10 animals (G1, G2 and G3), corresponding respectively to time of histological evaluation (7, 15 and 30 days). This was a paired study, a defect being induced in the parietal bone on either side of the median sagittal suture of the animals, being the left-hand side the experimental subgroup (filled by biomaterial) and the right control. The histological evaluation was performed by means of light microscopy. The collected data were submitted to the Fisher Exact test for comparison between the groups and to the McNemar test for comparison between the subgroups $(\mathrm{P}>5 \%)$. Results: The results showed no statistically significant differences between the groups and bone regeneration was similar at the different times of evaluation. Conclusions: Therefore, we concluded that $\beta$-tricalcium phosphate has not contributed significantly to repair process of defects induced in the cranium of Wistar rats.
\end{abstract}

Key words: Tricalcium phosphate, bone substitutes, rats.

\section{Introduction}

Of the various processes of tissue repair, bone repair is seen to be one of the most complex, being the subject of several research studies in the area of oral and maxillofacial surgery. Bone repair is a normal physiological process that permits the local growth of tissue with characteristics identical to those of the region's primary tissue (1). In the face of a major bone defect, the or- ganism becomes unable to regenerate bone and, unless other methods contribute their bone-repairing capacity, will produce scarring by fibrous tissue $(2,3)$.

A study on bone transplants concluded that autogenous bone is the best material for grafting (4-6). It is known, however, that this type of graft has a number of disadvantages, such as the use of a distant surgical donor area, postoperative discomfort, scars, longer duration 
of surgery and the risk of infection (7-10). Attempts have therefore been made to create or extract from nature materials that may serve as a substitute for bone or which, in association with autogenous bone, achieve the best possible repair and new bone formation.

$\beta$-tricalcium phosphate is a pure tricalcium phosphate in the beta phase, obtained by manipulating tricalcium phosphate at low temperature, thereby providing the product with greater stability when present in an aqueous medium. This material possesses the properties of radioopacity, osteoconduction and progressive absorption as the process of new bone formation proceeds $(11,12)$.

The present study sets out, by means of a histological assessment, to analyze the repair of bone defects in the cranium of Wistar rats at 7, 15 and 30 days, using $\beta$-tricalcium phosphate (Cerasorb ${ }^{\circledR}$ - Curasan AG, Kleinosheim, Germany) as filling material.

\section{Materials and Methods}

Thirty male Wistar rats with a mean age of 6 months and weights ranging from 423 to $510 \mathrm{~g}$ were used. Solid pellets (Labina ${ }^{\circledR}$ - Purina Nutriments) and water ad libitum were used as food. The rats were randomly allocated to three groups (G1, G2, G3) of 10 animals each. This was a paired study, the left-hand side being experimental (Subgroup A) and the right-hand side control (Subgroup B). The animals were anesthetized with ketamine hydrochloride (Francotar ${ }^{\circledR}$ - Vibarc) and xilazine hydrochloride (Xilazil ${ }^{\circledR}$ - Vibarc) diluted 1:1 with $0.2 \mathrm{ml}$ being applied for each $100 \mathrm{mg}$ of weight. The experimental defect ( $5 \mathrm{~mm}$ in diameter) was filled with granulated $\beta$-tricalcium phosphate in the specification $500-1000 \mu \mathrm{m}$ and the control side with blood from the bone diploe. The animals in Groups G1, G2 and G3 were postoperatively sacrificed at 7, 15 and 30 days, respectively. The surgical specimens were obtained by partial resection of the cranium, being fixed in $10 \%$ formol, and the specimens were sectioned in semiserials cross-sections $5 \mu \mathrm{m}$ thick and hematoxylin/eosin stained. The histological analysis was carried out in the Pathology Laboratory of the Pernambuco School of Dentistry (FOP); the histological parameters comprised the presence, quantity and type of inflammatory infiltrate, reaction to a foreign body, fibrous connective tissue, osteoblastic activity, formation of osteoid and new bone formation. Fisher's exact test for comparisons between the groups and McNemar's test for comparisons between the subgroups were used, with the level of significance set at $5 \%$.

\section{Results}

Vascular enlargement and areas of bleeding could be seen in the 10 animals evaluated in the experimental group at 7 days (Fig. 1). An inflammatory reaction was noted in only two animals. A reaction to a foreign body was present in one animal with fibrous connective tissue. Eight of the nine cases examined presented osteoblastic activity on the rim of the bone defect. In two animals a deposition of osteoid was observed on the rim of the implanted material and in one the deposition of osteoid occurred between the granules of the implanted material and close to the preexisting bone. The results of the control group at the same time of follow-up presented an inflammatory reaction in one animal, with no evidence of a reaction to a foreign body or deposition of osteoid, and new bone formation in two animals, the other results being similar to those of the experimental group (Table 1).

At 15 days neither an inflammatory infiltrate nor any reaction of the type produced by a foreign body were observed. Both fibrous connective tissue and osteoblastic activity were present in all cases. It was also found that among the granules of the implanted material there was connective tissue with a reticular appearance. We observed that there was new bone formation in all ten animals both at the rim of the defect and around the material (Fig. 2). In addition, there was a marked centripetal new bone formation in two animals in the experimental group, a result that occurred in only one animal in the control group. The other results in the latter were similar to those of the experimental group.

At 30 days an increase in the cellularity of the fibrous connective tissue and the onset of degradation of the implanted material with no reaction to a foreign body were observed (Fig. 3). The results for the control group were similar to those seen at 15 days.

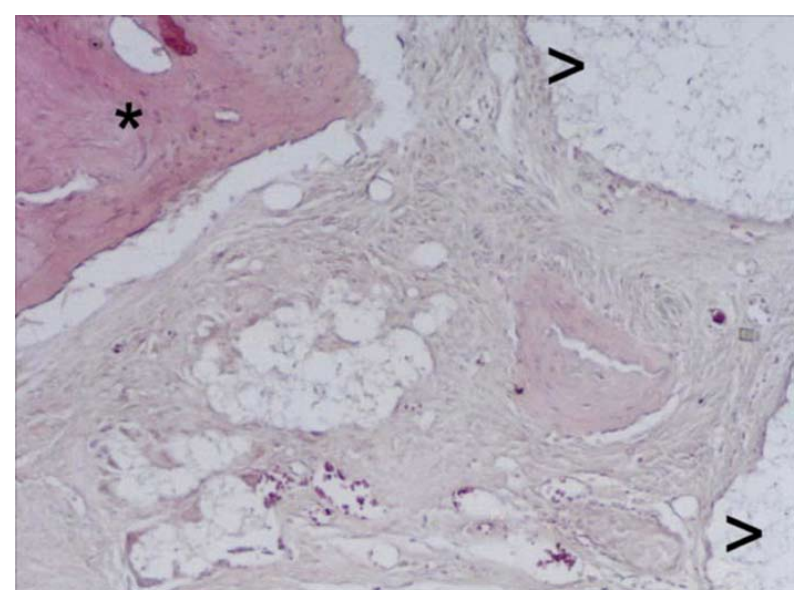

Fig. 1. Histological appearance of the bone wall(*) of the implanted material $(>)$ and congested blood vessels. Group 1A (H.E.). 
Table 1. Evaluation at 7 days in Group 1.

\begin{tabular}{lcc}
\hline Histological Parameters & Subgroup A & Subgroup B \\
& & \\
\hline Inflamatory Infiltrated & $22.2 \%$ & $11.1 \%$ \\
Reaction to a Foreing Body & $11.1 \%$ & $0 \%$ \\
Fibrous Conective Tissue & $100 \%$ & $100 \%$ \\
Osteoblastic Activity & $88.9 \%$ & $100 \%$ \\
Osteoid Formation & $33.3 \%$ & $0 \%$ \\
Bone Formation & $0 \%$ & $22.2 \%$ \\
\hline
\end{tabular}

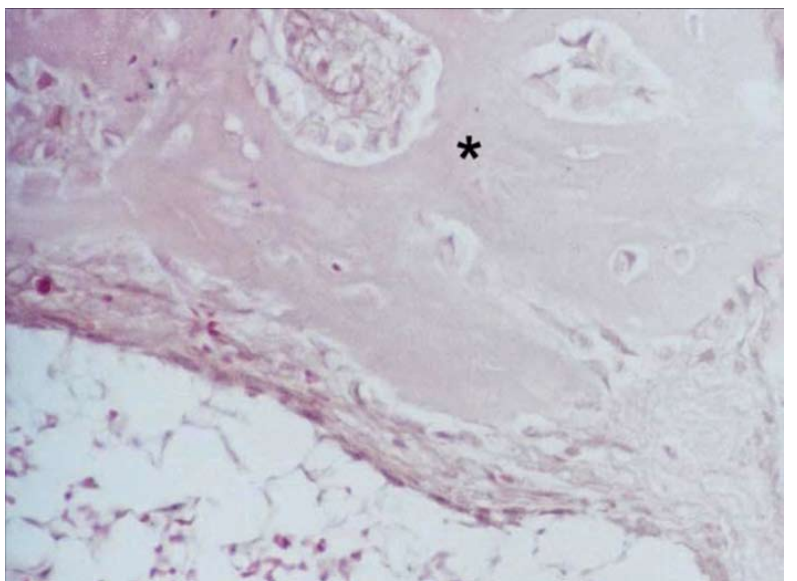

Fig. 2. Detail of the area of growth of new bone. Group 2A (H.E.).

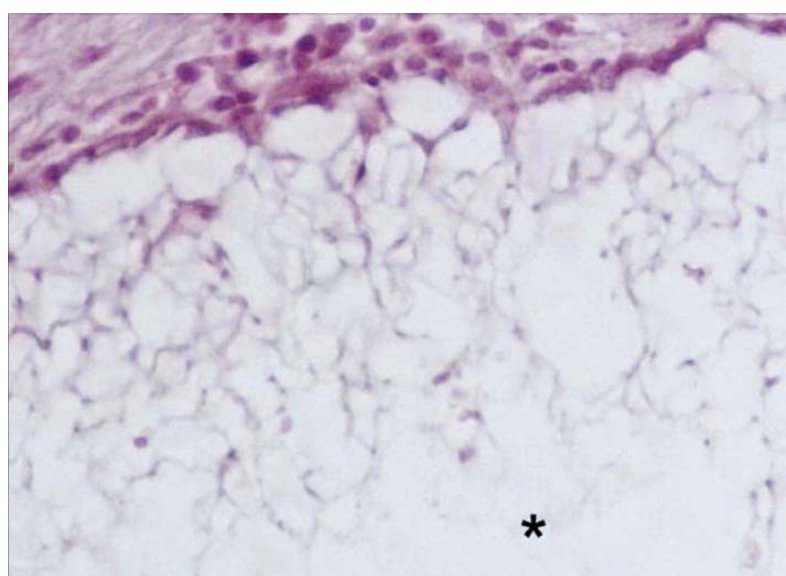

Fig. 3. In the region of the asterisk (*) loss of the reticular appearance of the conjunctive tissue can be seen, involving the implanted material, which is suggestive of its degradation. Group 3A (H.E. - 40X).

\section{Discussion}

In our study the inflammatory reactions observed were seen in only two rats in Group 1, Subgroup A, as expected, since this corresponds to the postoperative experiment at 7 days, in which the inflammatory reactions to the implanted material may, at the outset, inhibit the response to the initial repair by prolonging its inflammatory phase. An inflammatory reaction was also observed in one animal in Subgroup B (control), thus demonstrating that the inflammatory process is not solely the result of the material used, but rather is inherent in the very process of tissue repair, although this inflammation was milder in Subgroup B than in Subgroup A. These results are in agreement with the findings of Rueger et al. (13), in which the inflammatory response in the bone tissue of the animals studied was considered slight. In Groups 2 and 3 no inflammatory reaction was found, in agreement with the studies of Kamakura et al. (14), who observed the decline in the inflammatory response over time.

Reaction to a foreign body was seen in only one case, in Group 1, Subgroup A, thereby suggesting an isolated individual response. This type of reaction, however, was found by Rueger et al. (13) after the implantation of tricalcium phosphate in soft tissue, in which an intense reaction to a foreign body was observed. The orthotopic implantation in the experimental study in rats, however, presented a significantly weaker cell reaction, so this type of reaction does not appear to be a rare response, but tends to diminish over time in bone tissue.

In the three groups we assessed, the animals presented fibrous connective tissue. In Group 3, however, there was a considerable increase in cellularity, compared with Group 1, which may be due to a greater proliferation and a possible transformation of the undifferenti- 
ated cells into osteogenic cells, evidenced by the change in the cell morphology from spindle-shaped to rounded, no fibrosis being found around the granules of the implanted material. These findings match those of the studies of Kamakura et al. (14) and Neo et al. (15).

Osteoblastic activity was found in all the animals of Groups 1, 2 and 3, except in one animal in Subgroup A (experimental) of Group 1. As this was a paired study and the existence of osteoblastic activity was observed in Subgroup B (control), this feature is suggestive of a hypothesis of inhibition of osteoblastic activity by direct action of the implanted material.

It was possible to see the deposition of osteoid in three cases in Group 1, Subgroup A, but not in Subgroup B at the same time of follow-up, which allowed us to hypothesize the stimulation of the initial repair process mediated by the material, but the possibility that the semiserial cuts may not have revealed areas of osteiod deposition in Subgroup B of this group cannot be ruled out.

New bone formation could be seen in all the animals in Groups 2 and 3 in various forms, which suggests that in Group 3 (30 days) this new bone formation was more apparent than in Group 2 (15 days). In the evaluation of Group 1 (7 days) new bone formation was observed in only two cases in Subgroup B, which may suggest an individual response on the part of the animals.

A marked new bone formation was observed in two cases in Group 2, Subgroup A, but was apparent in only one animal in Subgroup B of this group; it thus appears that, in the second week of observation, Group 2, Subgroup A (experimental) presented a slight superiority in relation to the control group, probably as a result of stimulation of the implanted material.

In Group 3 the new bone formation was homogenous in Subgroups A and B, differing only in the new bone formation on the rim of the implanted material, in agreement with the study of Rueger et al. (13), who also found bone formation around tricalcium phosphate granules and who, after histomorphometric evaluation at 7, 21 and 40 days, demonstrated that the bone volume of neither the control nor the experimental groups presented any statistically significant differences.

Since the total filling of the defect by bone tissue did not occur in Group 3 (30 days), the critical limit was regarded as effective for this period. Nonetheless the experiment needs to be continued for longer periods in order that this observation may be further corroborated, for the tissue present in the area of the defect was shown to be amenable to bone repair without any cicatricial fibrosis being found in the central portion of the defect at the end of the period analyzed, as was seen by Bosh et al. (16), after evaluation of defects $5 \mathrm{~mm}$ in diameter in the cranium of Wistar rats at 6 and 12 months.

Although the present study did not set out to study the behavior of new bone formation after 30 days, it was observed, when the results were analyzed, that there is a need to undertake prospective studies, as well as evaluate the behavior of the material in relation to its permanence and resorption within the bone tissue.

\section{Conclusion}

On the basis of the results, it was possible to conclude that the restoration of bone defects in the cranium of Wistar rats at 7 days (Group 1), 15 days (Group 2) and 30 days (Group 3) in both Subgroup A (experimental) and Subgroup B (control) was similar and that no induction of bone formation by $\beta$-tricalcium phosphate was observed during this period.

\section{References}

\section{References with links to Crossref - DOI}

1. Figueiredo AS, Takita LC, Goldenberg S. Comparação entre a hidroxiapatita porosa de coral e o enxerto ósseo autógeno em coelhos. Acta Cir Bras. 1997;12:84-88.

2. Rios ALBB, Barbosa CEM, Abi Rached RSG, Gabrielli MFR, Okamoto T. Comportamento biológico de implantes de osso bovino anorgânico em arco zigomático de ratos: estudo histológico. Rev Odontol UNESP. 1996;25:87-101.

3. Mardas N, Kostopoulos L, Karring T. Bone and suture regeneration in calvarial defects by e-PTFE-membranes and demineralized bone matrix and the impact on calvarial growth: an experimental study in the rat. J Craniofac Surg. 2002;13:453-62.

4. Lin M, Overgaard S, Glerup H, Søballe K, Bünger C. Transforming growth factor-betal adsorbed to tricalciumphosphate coated implants increases peri-implant bone remodeling. Biomaterials. 2001;22:189-93.

5. Serra E Silva FM, Ricardo de Albergaria-Barbosa J, Mazzonetto R. Clinical evaluation of association of bovine organic osseous matrix and bovine bone morphogenetic protein versus autogenous bone graft in sinus floor augmentation. J Oral Maxillofac Surg. 2006;64:931-5.

6. Pripatnanont P, Nuntanaranont T, Vongvatcharanon S. Proportion of deproteinized bovine bone and autogenous bone affects bone formation in the treatment of calvarial defects in rabbits. Int J Oral Maxillofac Surg. 2009;38:356-62.

7. Kraal T, Mullender M, de Bruine JH, Reinhard R, de Gast A, Kuik DJ, et al. Resorbability of rigid beta-tricalcium phosphate wedges in open-wedge high tibial osteotomy: a retrospective radiological study. Knee. 2008;15:201-5.

8. Leutenegger A. [Integration and resorption of calcium phosphate ceramics in defect filling of fractures of the tibial head. Radiologic long-term results]. Helv Chir Acta. 1994;60:1061-6.

9. Tudor C, Srour S, Thorwarth M, Stockmann P, Neukam FW, Nkenke E, et al. Bone regeneration in osseous defects-application of particulated human and bovine materials. Oral Surg Oral Med Oral Pathol Oral Radiol Endod. 2008;105:430-6.

10. Knabe C, Koch C, Rack A, Stiller M. Effect of beta-tricalcium phosphate particles with varying porosity on osteogenesis after sinus floor augmentation in humans. Biomaterials. 2008;29:2249-58.

11. Kondo N, Ogose A, Tokunaga K, Ito T, Arai K, Kudo N, et al. Bone formation and resorption of highly purified beta-tricalcium phosphate in the rat femoral condyle. Biomaterials. 2005;26:5600-8. 12. Horch HH, Sader R, Pautke C, Neff A, Deppe H, Kolk A. Synthetic, pure-phase beta-tricalcium phosphate ceramic granules (Cerasorb) for bone regeneration in the reconstructive surgery of the jaws. Int J Oral Maxillofac Surg. 2006;35:708-13.

13. Rueger JM, Linhart W, Sommerfeldt D. [Biologic reactions to calcium phosphate ceramic implantations. Results of animal experiments]. Orthopade. 1998;27:89-95.

14. Kamakura S, Sasano Y, Homma H, Suzuki O, Kagayama M, 
Motegi K. Implantation of octacalcium phosphate (OCP) in rat skull defects enhances bone repair. J Dent Res. 1999;78:1682-7.

15. Neo M, Herbst H, Voigt CF, Gross UM. Temporal and spatial patterns of osteoblast activation following implantation of beta-TCP particles into bone. J Biomed Mater Res. 1998;39:71-6.

16. Bosch C, Melsen B, Vargervik K. Importance of the critical-size bone defect in testing bone-regenerating materials. J Craniofac Surg. 1998;9:310-6. 